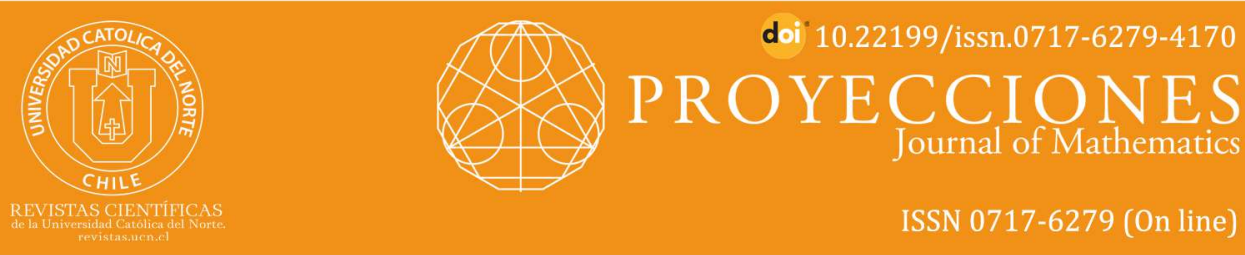

\title{
On locating chromatic number of Möbius ladder graphs
}

Redha Sakri ${ }^{1^{*}}{ }^{2}$ orcid.org/0000-0002-9750-4357 Moncef Abbas ${ }^{2}$

${ }^{1}$ University Djillali Bounaama Khemis Miliana, Fcs. of Sciences and Technology, Khemis Miliana, Algeria rsakri@usthb.dz ${ }^{2}$ University of Science and Technology Houari Boumediene. Fcs. of Mathematics, Algiers, Algeria moncef_abbas@yahoo.com

Received: 10 May 2020 | Accepted: 24 November 2020

\section{Abstract:}

In this paper, we are dealing with the study of locating chromatic number of Möbiusladders. We prove that Möbius-ladders $M n$ with $n$ even has locating chromatic number 4 if $n \neq 6$ and 6 if $n=6$.

Keywords: Möbius-ladders; Color code; Locating-chromatic number; Locating coloring.

$\operatorname{MSC}(2020): 05 C 12,05 C 15$.

\section{Cite this article as (IEEE citation style):}

R. Sakri and M. Abbas, "On locating chromatic number of Möbius ladder graphs", Proyecciones (Antofagasta, On line), vol. 40, no. 3 , pp. 659-669, 2021, doi: 10.22199/issn.0717-6279-4170

Article copyright: (C) 2021 Redha Sakri and Moncef Abbas. This is an open access article distributed under the terms of the Creative Commons License, which permits unrestricted use and distribution provided the original author and source are credited.

*Corresponding author 


\section{Introduction}

Let $G=(V, E)$ be a finite, simple and connected graph. The distance $d(u, v)$ between vertices $u$ and $v$ in $G$ is the length of the shortest path connecting $u$ and $v$ in $G$ and for a subset $S$ of $V(G)$, the distance between $u$ and $S$ is given by $d(u, S)=\min \{d(u, x) \mid x \in S\}$. The eccentricity $\epsilon(v)$ of a vertex $v$ is the greatest distance between $v$ and any other vertex. The diameter $\operatorname{diam}(G)$ of the graph is the maximum eccentricity of any vertex in the graph.

A k-coloring $c$ of a graph $G=(V, E)$ is a k-partition $\Pi=\left(V_{1}, V_{2}, \ldots, V_{k}\right)$ of $V(G)$ into independent sets, called colors. The color code of vertex $v$ of $G$, with respect to $\Pi$ is defined to be the ordered k-tuple $c_{\Pi}(v)=$ $\left(d\left(v, V_{1}\right), d\left(v, V_{2}\right), \ldots, d\left(v, V_{k}\right)\right)$. A k-coloring $c$ of $G$ is a locating coloring (or a locating k-coloring) of $G$ if any two distinct vertices of $G$ have distinct color codes with respect to $c$. The locating-chromatic number of $G$, denoted by $\chi_{L}(G)$, is the smallest $k$ such that $G$ admits a locating k-coloring.

The concept of locating coloring was first introduced by Erwin David et al. [1]. They established some bounds for the locating chromatic number of connected graph classes: paths, cycles, complete multipartite graphs and double stars. This concept has been also called resolving coloring and independent resolving partition [2].

For a certain locating-chromatic number, Chartrand et al. [3] characterized all graphs of order $n$ with locating-chromatic number $n-1$. Asmiati and Baskoro $[4,5]$ determined all graphs with locating-chromatic number 3. In [6], Asmiati et al. derived the locating-chromatic number for some class of trees, especially a class of trees obtained as an amalgamation of $n$ stars. Behtoei and Omoomi [7] gave the locating chromatic number for the cartesian product of any two graphs and gave the following definition and observation :

Definition 1. [7] Let $G$ be a connected graph. A vertex is called colorful if all of the colors appear in its closed neighborhood.

Observation 1. [7] In a locating coloring of $G$, there are no two colorful vertices that are assigned to the same color. Therefore, if there is a locating $k$-coloring of $G$, then there are at most $k$ colorful vertices.

The following theorem was proved in [1].

Theorem 2. [1] Let $G$ be a connected graph of order $n \geq 3$. Then $\chi_{L}(G)=$ $n$ if and only if $G$ is a complete multipartite graph. 
The following observation will be useful later.

Observation 3. To show that a given coloring $c$ is a locating coloring, it suffices to show that $c_{\Pi}(u) \neq c_{\Pi}(v)$ for vertices $u, v$ with $c(u)=c(v)$.

The Möbius ladder was originally introduced by Richard Guy and Frank Harary in 1967 [8]. The Möbius ladder on $n$ vertices $M_{n}$ is constructed by connecting vertices $v_{i}$ and $v_{j}$ in the cycle $C_{n}$ if $d\left(v_{i}, v_{j}\right)=\operatorname{diam}\left(C_{n}\right)$ (see Figure 1b). Some authors considred the case when $n$ is even $[9,10]$. The Möbius ladder graph $M_{n}$ for even positive integer $n$ is a graph can be obtained from the ladder $P_{\frac{n}{2}} \times P_{2}$ by joining the opposite endpoints of the two copies of $P_{\frac{n}{2}}$ (see Figure 1c). It can be also obtained by introducing a twist in a prism graph of order $n$. From Figure 1a, it is easy to see why this family is called the Möbius-ladders. Three different views of Möbiusladders $M_{20}$ are shown on Figure 1. We call $P_{1}=v_{1} v_{2} \ldots v_{\frac{n}{2}}$ the inner path and $P_{2}=v_{\frac{n+2}{2}} v_{\frac{n+4}{2}} \ldots v_{n}$ the outer path of the Möbius ladder graphs $M_{n}$.

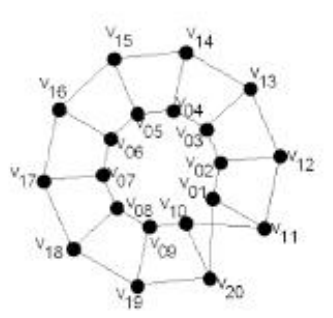

(a)

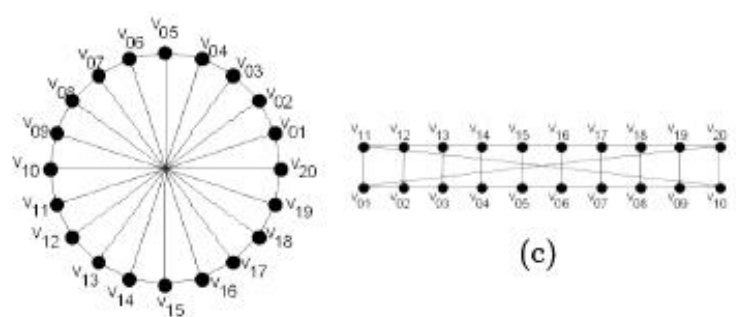

(b)

Figure 1: Three views of Möbius ladder $M_{20}$

Some parameters of Möbius ladders have been studied: strong metric dimension [11], H-antimagic covering [12], local metric dimension [13], metric dimension [14, 15], distance labelings [16] and skew chromatic index [17]. In the next section, we study the locating chromatic number of Möbius-ladders $M_{n}$ for $n$ even and we prove that $\chi_{L}\left(M_{n}\right)=4$ if $n \neq 6$ and $n$ even. 


\section{Main result}

We start by proving that the graph $M_{n}$ does not has a locating coloring with three colors and there is no 4-coloring or 5-coloring of $M_{6}$.

Lemma 1. $\chi_{L}\left(M_{6}\right)=6$.

Proof. It is easy to see that $M_{6}$ is isomorphic to $K_{3,3}$, the complete bipartite graph on 2 sets of 3 vertices each. Thus, again by theorem 2, we obtain that the locating chromatic number of $M_{6}$ is 6 .

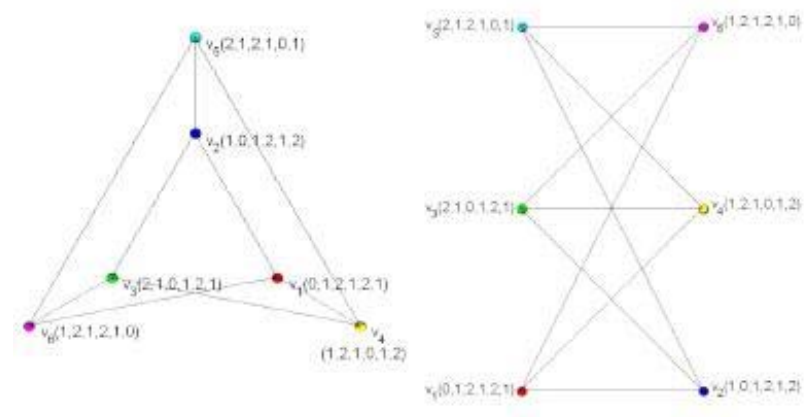

Figure 2: Locating 6-coloring of $M_{6}$

Theorem 2. If $n \geq 6$ and $n$ even, then $\chi_{L}\left(M_{n}\right) \geq 4$.

Proof. We will prove that $\chi_{L}\left(M_{n}\right) \geq 4$, by showing that there is no locating 3-coloring of $M_{n}$. Suppose that $M_{n}$ has locating 3-coloring, there exists an induced cycle of order 4 with 3 colors. Hence, there are two colorful vertices on this cycle with the same color, which is a contradiction with Observation 1 . Therefore $\chi_{L}\left(M_{n}\right) \geq 4$.

Lemma 3. Let $M_{n}$ be the Möbius ladder graph, $v_{i}$ be a vertex of $M_{n}$, $V_{3}=\left\{v_{1}, v_{\frac{n}{2}}\right\}$ and $V_{4}=\left\{v_{n}, v_{\frac{n+2}{2}}\right\}$. If $n \equiv 0 \bmod 4$ and $n \geq 8$ then:

$$
d\left(v_{i}, V_{4}\right)=\begin{gathered}
\left(v_{i}, V_{3}\right)+1 \text { if } i \in\left[1, \frac{n}{2}\right], \\
d\left(v_{i}, V_{3}\right)-1 \text { if } i \in\left[\frac{n+2}{2}, n\right],
\end{gathered}
$$

Proof. We have $d\left(v_{i}, V_{3}\right)=\min \left(d\left(v_{i}, v_{1}\right), d\left(v_{i}, v_{\frac{n}{2}}\right)\right)$. We distinguish two cases, depending on whether $d\left(v_{i}, V_{3}\right)=d\left(v_{i}, v_{1}\right)$ or $d\left(v_{i}, V_{3}\right)=d\left(v_{i}, v_{\frac{n}{2}}\right)$.

Case 1. $i \in\left[1, \frac{n}{4}\right] \cup\left[\frac{n+2}{2}, \frac{3 n}{4}\right]$.

In this case, we have $d\left(v_{i}, V_{3}\right)=d\left(v_{i}, v_{1}\right)$ and $d\left(v_{i}, V_{4}\right)=d\left(v_{i}, v_{\frac{n+2}{2}}\right)$. 
If $i \in\left[1, \frac{n}{4}\right]$ then $d\left(v_{i}, V_{4}\right)=d\left(v_{i}, v_{\frac{n+2}{2}}\right)=d\left(v_{i}, v_{1}\right)+d\left(v_{1}, v_{\frac{n+2}{2}}\right)=d\left(v_{i}, V_{3}\right)+$ 1.

If $i \in\left[\frac{n+2}{2}, \frac{3 n}{4}\right]$ then $\left.d\left(v_{i}, V_{3}\right)=d\left(v_{i}, v_{1}\right)=d\left(v_{i}, v_{\frac{n+2}{2}}\right)+d\left(v_{\frac{n+2}{2}}, v_{1}\right)\right)=$ $d\left(v_{i}, V_{4}\right)+1$.

Case 2. $i \in\left[\frac{n+4}{4}, \frac{n}{2}\right] \cup\left[\frac{3 n+4}{4}, n\right]$.

In this case, we have $d\left(v_{i}, V_{3}\right)=d\left(v_{i}, v_{\frac{n}{2}}\right)$ and $d\left(v_{i}, V_{4}\right)=d\left(v_{i}, v_{n}\right)$.

If $i \in\left[\frac{n+4}{4}, \frac{n}{2}\right]$ then $d\left(v_{i}, V_{4}\right)=d\left(v_{i}, v_{n}\right)=d\left(v_{i}, v_{\frac{n}{2}}\right)+d\left(v_{\frac{n}{2}}, v_{n}\right)=d\left(v_{i}, V_{3}\right)+$ 1.

If $i \in\left[\frac{3 n+4}{4}, n\right]$ then $d\left(v_{i}, V_{3}\right)=d\left(v_{i}, v_{\frac{n}{2}}\right)=d\left(v_{i}, v_{n}\right)+d\left(v_{n}, v_{\frac{n}{2}}\right)=d\left(v_{i}, V_{4}\right)+$ 1 .

Combining the two previous cases we get the following.

If $i \in\left[1, \frac{n}{4}\right] \bigcup\left[\frac{n+4}{4}, \frac{n}{2}\right]=\left[1, \frac{n}{2}\right]$, then $d\left(v_{i}, V_{4}\right)=d\left(v_{i}, V_{3}\right)+1$.

If $i \in\left[\frac{n+2}{2}, \frac{3 n}{4}\right] \bigcup\left[\frac{3 n+4}{4}, n\right]=\left[\frac{n+2}{2}, n\right]$, then $d\left(v_{i}, V_{3}\right)=d\left(v_{i}, V_{4}\right)+1$, so we have $d\left(v_{i}, V_{4}\right)=d\left(v_{i}, V_{3}\right)-1$.

Lemma 4. Let $M_{n}$ be the Möbius ladder graph with $n \geq 10, v_{i}$ a vertex of $M_{n}, V_{3}=\left\{v_{2}, v_{\frac{n}{2}}\right\}$ and $V_{4}=\left\{v_{n}, v_{\frac{n+4}{2}}\right\}$. If $n \equiv 2 \bmod 4$ and $n \geq 10$ then:

$$
\begin{array}{r}
\left(v_{i}, V_{3}\right)+1, \quad \text { if } 1 \in\left[2, \frac{n}{2}\right], \\
d\left(v_{i}, V_{4}\right)=d\left(v_{i}, V_{3}\right)-1, \quad \text { if } 1 \in\left[\frac{n+4}{2}, n\right], \\
d\left(v_{i}, V_{3}\right), \quad \text { if } 1 \in\left\{1, \frac{n+2}{2}\right\},
\end{array}
$$

Proof. We have $d\left(v_{i}, V_{3}\right)=\min \left(d\left(v_{i}, v_{2}\right), d\left(v_{i}, v_{\frac{n}{2}}\right)\right)$. We distinguish three cases,

Case 3. $i \in\left[2, \frac{n+2}{4}\right] \cup\left[\frac{n+4}{2}, \frac{3 n+2}{4}\right]$.

In this case, we have $d\left(v_{i}, V_{3}\right)=d\left(v_{i}, v_{2}\right)$ and $d\left(v_{i}, V_{4}\right)=d\left(v_{i}, v_{\frac{n+4}{2}}\right)$.

If $i \in\left[2, \frac{n+2}{4}\right]$, then $d\left(v_{i}, V_{4}\right)=d\left(v_{i}, v_{\frac{n+4}{2}}\right)=d\left(v_{i}, v_{2}\right)+d\left(v_{2}, v_{\frac{n+4}{2}}\right)=$ $d\left(v_{i}, V_{3}\right)+1$.

If $i \in\left[\frac{n+4}{2}, \frac{3 n+2}{4}\right]$, then $\left.d\left(v_{i}, V_{3}\right)=d\left(v_{i}, v_{2}\right)=d\left(v_{i}, v_{\frac{n+2}{2}}\right)+d\left(v_{\frac{n+2}{2}}, v_{1}\right)\right)=$ $d\left(v_{i}, V_{4}\right)+1$.

Case 4. $i \in\left[\frac{n+6}{4}, \frac{n}{2}\right] \cup\left[\frac{3 n+6}{4}, n\right]$.

In this case, we have $d\left(v_{i}, V_{3}\right)=d\left(v_{i}, v_{\frac{n}{2}}\right)$ and $d\left(v_{i}, V_{4}\right)=d\left(v_{i}, v_{n}\right)$. 
If $i \in\left[\frac{n+6}{4}, \frac{n}{2}\right]$ then $d\left(v_{i}, V_{4}\right)=d\left(v_{i}, v_{n}\right)=d\left(v_{i}, v_{\frac{n}{2}}\right)+d\left(v_{\frac{n}{2}}, v_{n}\right)=d\left(v_{i}, V_{3}\right)+$ 1.

If $i \in\left[\frac{3 n+6}{4}, n\right]$ then $d\left(v_{i}, V_{3}\right)=d\left(v_{i}, v_{\frac{n}{2}}\right)=d\left(v_{i}, v_{n}\right)+d\left(v_{n}, v_{\frac{n}{2}}\right)=d\left(v_{i}, V_{4}\right)+$ 1 .

Combining the two previous cases we get the following:

If $i \in\left[1, \frac{n}{4}\right] \bigcup\left[\frac{n+4}{4}, \frac{n}{2}\right]=\left[1, \frac{n}{2}\right]$ then $d\left(v_{i}, V_{4}\right)=d\left(v_{i}, V_{3}\right)+1$.

If $i \in\left[\frac{n+2}{2}, \frac{3 n}{4}\right] \bigcup\left[\frac{3 n+4}{4}, n\right]=\left[\frac{n+2}{2}, n\right]$ then $d\left(v_{i}, V_{3}\right)=d\left(v_{i}, V_{4}\right)+1$, so we have $d\left(v_{i}, V_{4}\right)=d\left(v_{i}, V_{3}\right)-1$.

Case 5. $i \in\left\{1, \frac{n+2}{2}\right\}$.

We have:

$d\left(v_{1}, V_{3}\right)=d\left(v_{1}, v_{2}\right)=1$ and $d\left(v_{1}, V_{4}\right)=d\left(v_{1}, v_{n}\right)=1$, so $d\left(v_{1}, V_{3}\right)=$ $d\left(v_{1}, V_{4}\right)$.

$d\left(v_{\frac{n+2}{2}}, V_{3}\right)=d\left(v_{\frac{n+2}{2}}, v_{\frac{n}{2}}\right)=1$ and $d\left(v_{\frac{n+2}{2}}, V_{4}\right)=d\left(v_{\frac{n+2}{2}}, v_{\frac{n+4}{2}}\right)=1$, so $d\left(v_{\frac{n+2}{2}}, V_{3}\right)=d\left(v_{\frac{n+2}{2}}, V_{4}\right)$.

So, for $i \in\left\{1, \frac{n+2}{2}\right\}$ we have $d\left(v_{i}, V_{3}\right)=d\left(v_{i}, V_{4}\right)$.

$\square$ The following two lemmas will be used to prove our main theorem.

Lemma 5. If $n \geq 8$ and $n \equiv 0 \bmod 4$ then $\chi_{L}\left(M_{n}\right)=4$.

Proof. We define 4-coloring $c$ of $M_{n}$ as follows (see figure 3a).

$$
\mathrm{c}\left(\mathrm{v}_{i}\right)= \begin{cases}1 & ,(i \text { odd and } i \in] 1, \frac{n}{2}[) \text { or }(i \text { even and } i \in] \frac{n+2}{2}, n[), \\ 2 & ,(i \text { even and } i \in] 1, \frac{n}{2}[) \text { or }(i \text { odd and } i \in] \frac{n+2}{2}, n[), \\ 3 & , i=1 \text { or } i=\frac{n}{2}, \\ 4 & , i=\frac{n+2}{2} \text { or } i=n .\end{cases}
$$

It suffices to show that the proper coloring $c$ is a locating coloring of $M_{n}$. Let be $v_{i}, v_{j}$ two distinct vertices at same distance from $V_{3}$. Without loss of generality, we can assume that $i<j$. We consider three cases depending on the distance of each vertex of $M_{n}$ from the color class $V_{3}$.

Case 6. $i \in] 1, \frac{n}{2}[$ and $j \in] \frac{n+2}{2}, n[$.

In this case, the vertex $v_{i}$ is in inner path $P_{1}$ and the vertex $v_{j}$ is in outer path $P_{2}$. By Lemma 5, we have $d\left(v_{i}, V_{4}\right)=d\left(v_{i}, V_{3}\right)+1$ and $d\left(v_{j}, V_{4}\right)=$ $d\left(v_{j}, V_{3}\right)-1$. Using the fact that $d\left(v_{i}, V_{3}\right)=d\left(v_{j}, V_{3}\right)$, we have $d\left(v_{i}, V_{4}\right) \neq$ $d\left(v_{j}, V_{4}\right)$, so $c_{\pi}\left(v_{i}\right) \neq c_{\pi}\left(v_{j}\right)$. 
Case 7. $i, j \in] 1, \frac{n}{2}[$.

In this case, the veritces $v_{i}, v_{j}$ are in inner path $P_{1}$. We have $j=\frac{n-2 i+2}{2}$; we can easily verify that: $d\left(v_{i}, V_{3}\right)=d\left(v_{\frac{n-2 i+2}{2}}, V_{3}\right)=i-1$ and by Lemma $5, d\left(v_{i}, V_{4}\right)=d\left(v_{\frac{n-2 i+2}{2}}, V_{4}\right)=i$. Note that $i$ and $\frac{n-2 i+2}{2}$ have different parity. The vertices $v_{i}, v_{\frac{n-2 i+2}{2}}$ must be in different color classes under $c$. so, we have $c_{\pi}\left(v_{i}\right) \neq c_{\pi}\left(\frac{v_{n-2 i+2}}{2}\right)$.

Case 8. $i, j \in] \frac{n+2}{2}, n[$.

In this case, the veritces $v_{i}, v_{j}$ are in outer path $P_{2}$. We have $j=\frac{3 n-2 i+2}{2}$. We can easily verify that: $d\left(v_{i}, V_{3}\right)=d\left(v_{\frac{3 n-2 i+2}{2}}, V_{3}\right)=i-\frac{n}{2}$ and by Lemma $5, d\left(v_{i}, V_{4}\right)=d\left(v_{\frac{3 n-2 i+2}{2}}, V_{4}\right)=i-\frac{n}{2}-1$. Note that $i$ and $\frac{3 n-2 i+2}{2}$ have different parity, the vertices $v_{i}, v_{\frac{3 n-2 i+2}{2}}$ must be in different color classes under $c$, we have $c_{\pi}\left(v_{i}\right) \neq c_{\pi}\left(\frac{v_{\frac{3 n-2 i+2}{2}}}{2}\right)$.

Case 9. $i, j \in\left\{1, \frac{n}{2}, \frac{n+2}{2}, n\right\}$.

The vertex $v_{1}$ is adjacent to vertex with color 2 and the vertex $v_{\frac{n}{2}}$ is not adjacent to any vertex with color 2 thus $d\left(v_{i}, V_{2}\right)=1$ and $d\left(v_{\frac{n}{2}}, V_{2}\right) \neq 1$. So we have $c_{\pi}\left(v_{1}\right) \neq c_{\pi}\left(v_{\frac{n}{2}}\right)$.

The vertex $v_{n}$ is adjacent to vertex with color 2 and $v_{\frac{n+2}{2}}$ is not adjacent to any vertex with color 2 , thus $d\left(v_{\frac{n+2}{2}}, V_{2}\right)=1$ and $d\left(v_{n}, V_{2}\right) \neq 1$, so we have $c_{\pi}\left(v_{n}\right) \neq c_{\pi}\left(v_{\frac{n+2}{2}}\right)$.

The vertices $v_{1}, v_{n}$ are adjacent, they must have different color,so we have $c_{\pi}\left(v_{1}\right) \neq c_{\pi}\left(v_{n}\right)$.

It's easy to see that $c_{\pi}\left(v_{1}\right) \neq c_{\pi}\left(v_{n}\right) \neq\left(v_{\frac{n}{2}}\right) \neq c_{\pi}\left(v_{\frac{n+2}{2}}\right)$.

From all previous cases, we can see that all vertices in $M_{n}$ have different color codes, so $\chi_{L}\left(M_{n}\right) \leq 4$. Using Theorem 2, we have $\chi_{L}\left(M_{n}\right)=4$ when $n \equiv 0 \bmod 4$. So the lemma is proved.

Lemma 6. If $n \geq 8$ and $n \equiv 2 \bmod 4$ then $\chi_{L}\left(M_{n}\right)=4$.

Proof. We define 4-coloring $c$ of $M_{n}$ as follows (see figure 3a).

$$
\mathrm{c}\left(\mathrm{v}_{i}\right)= \begin{cases}1 & , i \text { odd and } i \notin\left\{\frac{n}{2}, \frac{n+4}{2}\right\}, \\ 2 & , i \text { even and } i \notin\{2, n\}, \\ 3 & , i \in\left\{2, \frac{n}{2}\right\}, \\ 4 & , i \in\left\{\frac{n+4}{2}, n\right\} .\end{cases}
$$

It suffices to show that the proper coloring $c$ is a locating coloring of $M_{n}$. We analyse two cases depending on the distance of each vertex of $M_{n}$ 
from the color class $V_{3}$. Let $v_{i}, v_{j}$ be two distinct vertices at same distance from $V_{3}$, without loss of generality we can assume that $i<j$.

Case 10. $i \in] 2, \frac{n}{2}[$ and $j \in] \frac{n+4}{2}, n[$.

In this case, the vertex $v_{i}$ is in inner path $P_{1}$ and the vertex $v_{j}$ is in outer path $P_{2}$. By lemma 6 we have $d\left(v_{i}, V_{4}\right)=d\left(v_{i}, V_{3}\right)+1$ and $d\left(v_{j}, V_{4}\right)=$ $d\left(v_{j}, V_{3}\right)-1$. Using the fact that $d\left(v_{i}, V_{3}\right)=d\left(v_{j}, V_{3}\right)$, we have $d\left(v_{i}, V_{4}\right) \neq$ $d\left(v_{j}, V_{4}\right)$, thus $c_{\pi}\left(v_{i}\right) \neq c_{\pi}\left(v_{j}\right)$.

Case 11. $i, j \in] 2, \frac{n}{2}[$

In this case, the vertices $v_{i}, v_{j}$ are in inner path $P_{1}$, and we have $j=\frac{n-2 i+4}{2}$. We can verify that $d\left(v_{i}, V_{3}\right)=d\left(v_{\frac{n-2 i+2}{2}}, V_{3}\right)=i-2$. By lemma 4 , we have $d\left(v_{i}, V_{4}\right)=d\left(v_{\frac{n-2 i+4}{2}}, V_{4}\right)=i-1$. Note that $i$ and $\frac{n-2 i+4}{2}$ have different parity, the vertices $v_{i}, v_{\frac{n-2 i+4}{2}}$ must be in different color classes under $c$. So we have $c_{\pi}\left(v_{i}\right) \neq c_{\pi}\left(v_{\frac{n-2 i+4}{2}}\right)$.

Case 12. $i, j \in] \frac{n+4}{2}, n[$.

In this case, the veritces $v_{i}, v_{j}$ are in outer path $P_{2}$, and we have $j=$ $\frac{3 n-2 i+4}{2}$. We can easily verify that $d\left(v_{i}, V_{3}\right)=d\left(v_{\frac{3 n-2 i+4}{2}}, V_{3}\right)=\frac{2 i-n-2}{2} B y$ lemma $6 d\left(v_{i}, V_{4}\right)=d\left(v_{\frac{3 n-2 i+4}{2}}, V_{4}\right)=\frac{2 i-n-4}{2}$. Note that $i$ and $\frac{3 n-2 i+4}{2}$ have different parity, the vertices $v_{i}, v_{\frac{3 n-2 i+4}{2}}$ must be in different color classes under $c$. So we have $c_{\pi}\left(v_{i}\right) \neq c_{\pi}\left(\frac{v_{\frac{3 n-2 i+4}{2}}}{2}\right)$.

Case 13. $i, j \in\left\{2, \frac{n}{2}, \frac{n+4}{2}, n\right\}$.

The vertex $v_{2}$ is adjacent to vertex with color 1 and the vertex $v_{\frac{n}{2}}$ is not adjacent to any vertex with color 1 , thus $d\left(v_{1}, V_{1}\right)=1$ and $d\left(v_{\frac{n}{2}}, V_{1}\right) \neq 1$. So we have $c_{\pi}\left(v_{1}\right) \neq c_{\pi}\left(v_{\frac{n}{2}}\right)$.

The vertex $v_{n}$ is adjacent to vertex with color 1 and $v_{\frac{n+4}{2}}$ is not adjacent to any vertex with color 1 , thus $d\left(v_{\frac{n+4}{2}}, V_{1}\right) \neq 1$ and $d\left(v_{n}, V_{1}\right)=1$. So we have $c_{\pi}\left(v_{n}\right) \neq c_{\pi}\left(v_{\frac{n+4}{2}}\right)$.

The vertices $v_{2}, v_{\frac{n+4}{2}}^{2}$ are adjacent; they must have different color, so we have $c_{\pi}\left(v_{2}\right) \neq c_{\pi}\left(v_{\frac{n+4}{2}}\right)$.

It's easy to deduce that $c_{\pi}\left(v_{2}\right) \neq c_{\pi}\left(v_{n}\right) \neq\left(v_{\frac{n}{2}}\right) \neq c_{\pi}\left(v_{\frac{n+4}{2}}\right)$.

Case 14. $i, j \in\left\{1, \frac{n+2}{2}\right\}$.

The vertices $v_{1}, v_{\frac{n+2}{2}}$ are adjacent, they must have different color, $c_{\pi}\left(v_{1}\right) \neq$ $c_{\pi}\left(v_{\frac{n+2}{2}}\right)$. 
From all cases, we can see that all vertices in $M_{n}$ have different color codes, so $\chi_{L}\left(M_{n}\right) \leq 4$. By using Theorem 2 , we have $\chi_{L}\left(M_{n}\right)=4$ when $n \equiv$ $2 \bmod 4$. So the lemma is proved.

Combining Lemma 1, Lemma 5 and Lemma 6, we get the following theorem.

Theorem 7. If $n \geq 6$ and $n$ is even then

$$
\chi_{L}\left(M_{n}\right)= \begin{cases}4 & n \neq 6 \\ 6 & n=6\end{cases}
$$

Proof. For $n \geq 8$, we consider two cases depending on the parity of $\frac{n}{2}$. If $\frac{n}{2}$ is even then $n \equiv 0 \bmod 4$. By lemma 5 , we have $\chi_{L}\left(M_{n}\right)=4$.

If $\frac{n}{2}$ is odd then $n \equiv 2 \bmod 4$ and, by lemma 6 , we have $\chi_{L}\left(M_{n}\right)=4$.

Then, again by lemma 1 , we have $\chi_{L}\left(M_{6}\right)=6$. So, the theorem is proved.

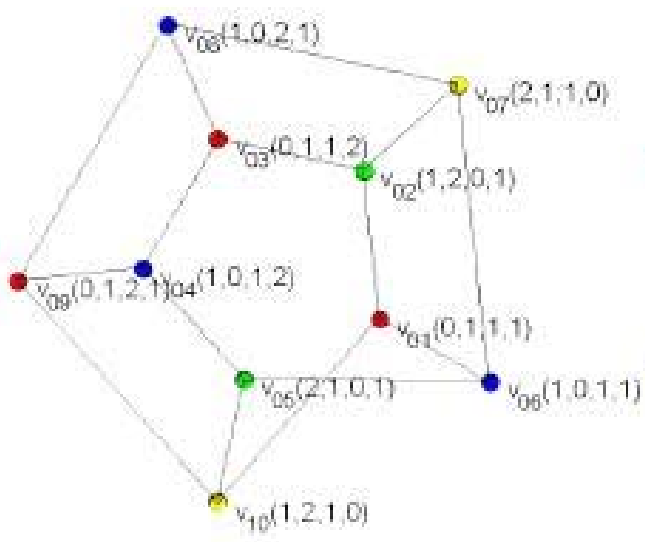

(a) $M_{10}$

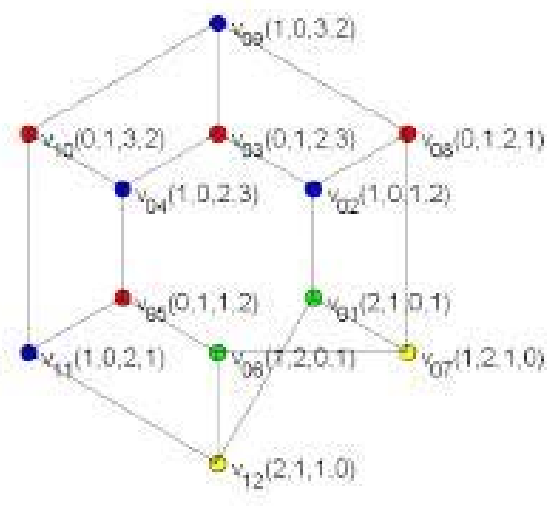

(b) $M_{12}$

Figure 3: 4-Locating Colccing of $M_{10}$ and $M_{12}$ 


\section{Conclusion}

We considered the Möbius ladders graphs $M_{n}$ and we proved that the locating chromatic number of $M_{n}$ with $\mathrm{n}$ even is 4 if $n=6$ and 6 if $n=6$. In the future, we will study the Möbius ladders graphs $M_{n}$ for $n$ odd and consider more families of graph in the context of locating chromatic number.

\section{References}

[1] G. Chartrand, D. Erwin, M. A. Henning , P. J. Slater, and P. Zhang, "The locating-chromatic number of a graph", Bulletin Institute Combinatorial Application, vol. 36, pp. 89-101, 2002.

[2] V. Saenpholphat and P. Zhang, "Conditional resolvability in graphs: a survey", International journal of mathematics and mathematical sciences, vol. 2004, Art ID. 247096, 2004, doi: 10.1155/ S01 61171204311403

[3] G. Chartrand, D. Erwin, M. A. Hennings, P. J. Slater, and P. Zhang, "Graphs of order $\mathrm{n}$ with locating-chromatic number n-1", Discrete mathematics, vol. 269, no. 1-3, pp. 65-79, 2003, doi: 10.1016/ S0012-365X(02)00829-4

[4] A. Asmiati and E. T. Baskoro, "Characterizing all graphs containing cycles with locating-chromatic number 3", AIP conference proceedings, vol. 1450, no. 1, pp. 351-357, 2012, doi: 10.1063/1.4724167

[5] E. T. Baskoro and A. Asmiati, "Characterizing all trees with locatingchromatic number 3", Electronic journal of graph theory and applications, vol. 1, no. 2, pp. 109-117, 2013, doi: 10.5614/ ejgta. 2013.1.2.4

[6] A. Asmiati, H. Assiyatun, and E. T. Baskoro, "Locating-chromatic number of amalgamation of stars", Journal of mathematical and fundamental sciences, vol. 43, no. 1, pp. 1-8, 2011, doi: 10.5614/itbj.sci.2011. 43.1 .1

[7] A. Behtoei and B. Omoomi, "On the locating chromatic number of Cartesian product of graphs", 2012, arXiv:1106.3453v3

[8] R. K. Guy and F. Harary, "On the Mobius ladders", Canadian mathematical bulletin, vol. 10, no. 4, pp. 493-498, 1967, doi: 10.4153/CMB1967-046-4 
[9] N. Biggs, R. Damerell, and D. Sands, "Recursive families of graphs", Journal of combinatorial theory, series B, vol. 12, no. 2, pp. 123-131, 1972, doi: 10.1016/ 0095-8956(72)90016-0

[10] J. P. McSorley, "Counting structures in the Möbius ladder", Discrete mathematics, vol. 184, no. 1-3, pp. 137-164, 1998, doi: 10.1016/ S0012365X(97)00086-1

[11] M. Widyaningrum and T. A. Kusmayadi, "On the strong metric dimension of sun graph, windmill graph and Möbius ladder graph", Journal of physics: conference series, vol. 1008, Art. ID. 012032, 2018, doi: 10.1088/1742-6596/1008/1/ 012032

[12] N. Indriyani and T. Sri Martini, "Super (a, d)-H-antimagic covering of Möbius ladder graph", Journal of physics: conference series, vol. 1008, Art. ID. 012047, april 2018, doi: 10.1088/ 1742-6596/ 1008/ 1/ 012047

[13] W. Tri Budianto and T. Atmojo Kusmayadi, "The local metric dimension of starbarbell graph, $\mathrm{Km}_{\mathrm{m}} \odot \mathrm{P}_{\mathrm{n}}$ graph and Möbius ladder graph", Journal of physics: conference series, vol. 1008, Art. ID. 012050, 2018, doi: 10.1088/ 1742-6596/ 1008/ 1/ 012050

[14] M. Munir, A. R. Nizami, Z. Iqbal, and H. Saeed, "Metric dimension of the Möbius ladder", Ars combinatoria, vol. 135, pp. 249-256, 2017. [On line]. Available: https:/ / bit.ly/ 330sgJW

[15] M. Ali, G. Ali, M. Imran, A. Q. Baig, and M. K. Shafiq, "On the metric dimension of Möbius ladders", Ars combinatoria, vol. 105, pp. 403-410, 2012. [On line]. Available: https:/ / bit.ly/ 3e4q8XC

[16] A. Rojas and K. Diaz, "Distance labelings of Möbius ladders", Degree of Bachelor of Science, Worcester Polytechnic Institute, 2013. [On line]. Available: https:/ / bit.ly/ 3303PfC

[17] M. J. Punitha and S. Rajakumari, "Skew chromatic index of comb, ladder and Möbius ladder graphs", International journal of pure and applied mathematics, vol. 101, no. 6, pp. 1003-1011, 2015, doi: 10.12732/ ijpam.v101i6.18 